\title{
Primeiras Histórias do Ensino de Biologia: uma análise bibliométrica
}

\author{
First Histories of Biology Teaching: a bibliometric analysis \\ Primeras Historias de la Enseñanza de la Biología: un análisis \\ bibliométrico
}

Peterson Fernando Kepps da Silvaㄹ; ${ }^{1}$ Lavínia Schwantes ${ }^{1}$

\section{RESUMO}

O presente trabalho tem como objetivo realizar um mapeamento das produções científicas em História do Ensino de Biologia. A metodologia utilizada foi a pesquisa bibliométrica através de buscas na revista científica História e Filosofia da Biologia, Portal de periódicos da CAPES, e biblioteca eletrônica SciELO. Trata-se de um estudo quantitativo e descritivo de produções que envolvessem História do Ensino de Biologia. Analisamos nos títulos dos trabalhos as palavras "biologia", "ensino" e "disciplina" ou qualquer vocábulo/expressão que pudesse remeter a ideia de História do Ensino de Biologia. Foram considerados todos os trabalhos recuperados, estivessem eles na língua inglesa, portuguesa ou espanhola. O total de documentos recuperados foi de 1545. Para a análise, além de apresentar quantitativamente os dados, agrupamos os trabalhos recuperados na pesquisa em categorias comuns. A análise permitiu perceber que há um número reduzido de estudos sobre história do ensino de biologia, comparado com a história da educação matemática, por exemplo. A partir das buscas fica evidente para que a História do Ensino de Biologia faz parte de um campo de pesquisa e estudos pouco explorados.

Palavras-chave: Ensino de Biologia; História do Ensino de Biologia; História da Educação.

\begin{abstract}
The present work aims to map scientific productions in the History of Biology Teaching. The methodology used was bibliometric research, and we research on the journal History and Philosophy of Biology, CAPES journals portal, and SCIELO electronic library. It is a quantitative and descriptive study of productions involving the History of Biology Teaching. We analyzed in the titles of the works the words "biologia" (biology), "ensino" (teaching) and "disciplina" (discipline) or any word/expression that could refer to the idea of History of Biology Teaching. All recovered works were considered, whether they were in English, Portuguese or Spanish. The total number of documents recovered was 1545. For the analysis, in addition to presenting the data quantitatively, we grouped the works retrieved in the research into common categories. The analysis showed that there is a small number of studies on the history of teaching biology, compared to the history of mathematics education, for example. From the searches it becomes evident that the History of Biology Teaching is part of a little explored field of research and studies.
\end{abstract}

Keywords: Biology Teaching; History of Biology Teaching; History of Education.

\footnotetext{
${ }^{1}$ FURG - Universidade Federal do Rio Grande, Rio Grande/RS - Brasil.
} 


\section{RESUMEN}

El presente trabajo tiene como objetivo mapear las producciones cientificas en la Historia de la Enseñanza de la Biología. La metodología utilizada fue la investigación bibliométrica a través de búsquedas en la revista científica Historia y filosofía de la biología, el portal de revistas CAPES y la biblioteca electrónica SciELO. Es un estudio cuantitativo y descriptivo de producciones relacionadas con la enseñanza de la historia de la biología. Analizamos en los títulos de las obras las palabras "biología" (biología), "ensino" (enseñanza) y "disciplina" (disciplina) o cualquier palabra / expresión que pudiera referirse a la idea de Historia de la enseñanza de la biología. Se consideraron todas las obras recuperadas, ya sea en inglés, portugués o español. El número total de documentos recuperados fue de 1545. Para el análisis, además de presentar los datos cuantitativamente, agrupamos los trabajos recuperados en la investigación en categorías comunes. El análisis mostró que hay un pequeño número de estudios sobre la historia de la enseñanza de biología, en comparación con la historia de la educación matemática, por ejemplo. De las búsquedas se hace evidente que la Enseñanza de Historia de la Biología es parte de un campo poco explorado de investigación y estudios.

Palabras clave: Enseñanza de biología; Historia de la enseñanza de la biología; Historia de la educación.

\section{INTRODUÇÃO}

O ensino de ciências tem estado, nas últimas décadas, sob o foco de estudos e análises. Pesquisadores e professores mostram-se interessados em discutir os modos como são conduzidos o ensino, as diferentes metodologias de ensino utilizadas em sala de aula, a inserção de novos conteúdos/assuntos na escola, bem como de temas na Educação Básica como história e filosofia da ciência. Krasilchik (2000), Auler (2002), Delizoicov, Angotti e Pernambuco (2002) são alguns dos estudiosos brasileiros reconhecidos que contribuíram significativamente para o entendimento destes assuntos e para 0 alargamento das discussões no ensino de ciências.

A Biologia, a Química e a Física nem sempre fizeram parte da grade curricular dos sistemas educacionais. Antes do século XIX, os estudos eram voltados, na maioria das vezes, apenas para as línguas clássicas e Matemática. Com o passar do tempo, as "ciências da natureza", como a denominamos nos dias de hoje, conquistaram o posto de disciplinas escolares e assumiram espaço no currículo escolar. Junto a isso, opiniões divergentes sobre a ênfase que o ensino deveria assumir ganharam relevo: como a visão de ciência voltada à resolução de problemas do cotidiano; ou, por outro lado, a prerrogativa de ensinar para formar futuros cientistas, com base em um ensino livresco, pautado em definições, teorias e "experimentos cujos resultados são previamente conhecidos" (KONDER, 1998, p. 32).

Muitas mudanças de perspectivas e dos rumos do ensino de ciências aconteceram. Podemos ilustrar com a "batalha espacial", ocorrida no período de 1960, na qual os Estados Unidos da América fez altos investimentos na educação para formar futuros cientistas e garantir a hegemonia do país na conquista do espaço. Nesta linha, tinha-se uma visão progressista da ciência e essa era encarada como provedora direta do bem-estar social o que, de acordo Krasilchik (2000), refletiu na importância dada ao ensino de ciências.

Por outra via, os desastrosos e dramáticos acontecimentos sociais e ambientais fizeram com que essa ideia demasiada de valorização da ciência e da tecnologia passasse a ser mais fortemente 
questionada. "O sonho de que o avanço científico e tecnológico geraria a redenção dos males da humanidade estava chegando ao fim", aponta Linsingen (2007, p. 4). As guerras e catástrofes ambientais estabeleceram um clima de tensão, o que, a título de exemplo, desencadeou no surgimento de movimentos que visavam considerar a tecnologia e a ciência de forma integrada com a sociedade.

Mesmo que brevemente, referimos-nos, até agora, ao ensino de ciências de um modo mais amplo e localizado no século XX. Mas queremos recuar no tempo e delimitar um pouco o terreno deste trabalho. O principal objeto do nosso estudo, que ultrapassa os limites desse artigo e se torna tema de doutoramento do primeiro autor, é uma abordagem histórica do Ensino de Biologia no Brasil Imperial (1822-1889). O que isso significa? Primeiro, é preciso ter a noção de que o Ensino de Biologia constitui-se enquanto um "campo de estudos, de pesquisas e de práticas sustentada por uma comunidade de educadores e de pesquisadores cuja referência são atividades de cunho didático que conferem sentidos a esse campo." (MARANDINO, SELLES e FERREIRA, 2009, p. 21). Ou seja, tanto espaços formais (principalmente, a escola) quanto espaços não formais (museus, exposições, cursos, entre outros meios que partilham processos que podem envolver o ensino de biologia) são concebidos como foco de estudos.

Em segundo lugar, é preciso considerar a relevância do trabalho histórico para as pesquisas em educação. Desenvolver a história do Ensino de Biologia torna-se importante para compreendermos os processos que a constituíram. Também nos ajuda a compreender e problematizar o domínio desta ciência enquanto disciplina escolar atualmente. Isto é, contribui para questionarmos os modos de seleção e organização de conhecimentos, desconfiarmos de propostas curriculares que visem somente à mudança de conteúdos que compõem a disciplina de Biologia; bem como a atentar para as formas como nós, professores, conduzimos e encaramos essa disciplina escolar.

Decerto, consideramos que na história do Ensino de Biologia existiram influências econômicas, políticas, sociais, culturais exercidas pela Europa, especialmente a partir do século XIX. Porém, temos buscado atentar para os movimentos que aconteceram no Brasil. Essa forma de conduzirmos a pesquisa não descredita o protagonismo europeu como epicentro do "surgimento" do iluminismo e da ciência, e, nem dos vários conhecimentos das Ciências Naturais que hoje fazem parte do que é ensinado na escola. Em verdade, apenas nos situamos, temporal e espacialmente, em outro local e nos mobilizamos a olhar os contornos da emergência do Ensino de Biologia ocorridos no Brasil.

Assim, o trabalho neste artigo tem como objetivo realizar um mapeamento da produção do conhecimento científico em História do Ensino de Biologia, publicados na Revista de Filosofia e História da Biologia, no Portal de periódicos da CAPES, e na biblioteca eletrônica SciELO. Dito isso, colocamos aqui algumas indagações: quais temas do ensino de Biologia foram mais recorrentes nas buscas? Quais tipos de histórias do ensino de biologia estão sendo contadas e publicizadas nas plataformas analisadas? Quais (ou qual) assuntos e/ou ênfases podem necessitar maior atenção pela comunidade de pesquisadores interessados na História do Ensino de Biologia?

\section{METODOLOGIA}

A metodologia utilizada para desenvolver parte deste trabalho foi a pesquisa bibliométrica. A bibliometria, segundo Pritchard (apud SANTOS e KOBASHI, 2009, p. 157), "é caracterizada como o conjunto de métodos e técnicas quantitativos para a gestão de bibliotecas e instituições envolvidas 
com o tratamento de informação". Neste sentido, ela utiliza-se de métodos estatísticos e matemáticos para mapear a produção científica de forma quantitativa.

Pode-se compreender a bibliometria como um empreendimento metodológico quantitativo da produção de conhecimento científico; ou seja, uma técnica que possibilita mapear esta produção e disseminação do conhecimento. De modo sintético, as técnicas empregadas na bibliometria perpassam desde o uso correto dos descritores ou palavras-chave para a busca, a forma de organizar os dados recuperados até a utilização das informações presentes nestes dados.

Além disso, pesquisas bibliométricas são de suma importância para a ciência, devido ao grande número de base de dados, o que permite ao pesquisador mapear e quantificar os trabalhos que estão sendo desenvolvidos em determinada área. Este mapeamento e quantificação das produções pode direcionar os novos passos, investimentos e produções da área científica. Assim como nos permite ter uma visão geral da produção científica e acadêmica; e analisar o conhecimento do que já foi produzido sobre determinado tema.

A bibliometria, de acordo com Guedes e Borschiver (2005), corrobora na organização e sistematização das informações científicas e tecnológicas. Acreditamos que, junto a esse mapeamento quantitativo, faz-se importante estudar os diferentes trabalhos de pesquisa já realizados na área de interesse de estudos. O que pode ser entendido como um trabalho de cunho qualitativo. Conquanto, neste trabalho, focamos na pesquisa quantitativa em bancos de dados disponibilizados na internet. Não avançamos para um empreendimento, uma análise qualitativa das produções devido aos resultados da pesquisa - que será discutido nas seções posteriores.

Buscamos mapear no portal de periódicos da Coordenação de Aperfeiçoamento de Pessoal de Nível Superior (CAPES), na Scientific Electronic Library Online (SciELO) e na revista Filosofia e História da Biologia (RFHB) produções que envolvem História do Ensino ou História da Disciplina de Biologia. A inserção do vocábulo "disciplina" nas buscas se deu pela possível vinculação do mesmo com o nosso tema de estudo e para termos acesso a um número maior de produções. Para tanto, observamos nos títulos das produções (artigos, teses, dissertações...) as palavras "biologia", "ensino" e "disciplina", e atentamos para qualquer vocábulo ou expressão que pudesse remeter a ideia de História do Ensino de Biologia. Foram realizadas buscas por "assunto" e considerados todos os trabalhos recuperados, estivessem eles na língua inglesa, portuguesa ou espanhola.

Escolhemos como fonte de busca o portal de periódicos da CAPES e a biblioteca eletrônica SciELO pela amplitude de periódicos que estas plataformas digitais possuem e pela facilidade de acesso à literatura científica. Localizamos a revista Filosofia e História da Biologia pelo WebQualis 2013 da CAPES; e a escolha se deu por ser um periódico especificamente destinado aos estudos da área de História e Filosofia da Biologia, o que pode nos trazer informações direcionadas do que está sendo produzido no campo, que é a nossa área de interesse. Já o período que realizamos a busca nos três canais supracitados foi de 14 a 20 de abril de 2020.

Em um primeiro momento, analisamos o número de publicações da RFHB, referente ao período de 2006 - 2019 (o que contempla todos os trabalhos publicados na revista até a finalização do presente artigo). Em um segundo momento, realizamos uma análise restrita nos títulos dos trabalhos. Buscamos observar quais temáticas/áreas da História e Filosofia da Biologia contemplariam nosso tema de interesse. Contabilizamos os temas apresentados nos trabalhos publicados na revista por 
meio das palavras mencionadas anteriormente (biologia, ensino e disciplina) e atentamos para as expressões/termos que pudessem enfocar ao nosso objeto/área de estudo.

No Portal da CAPES, procedemos da seguinte maneira: inicialmente, nas buscas, utilizamos as palavras-chave: história and biologia, o que resultou em mais de seis mil documentos recuperados. Devido à quantidade de trabalhos, realizamos nova busca com os descritores específicos da pesquisa: "história do ensino de biologia" e "história da disciplina de biologia", e não obtivemos resultado. Por isso, escolhemos ampliar as buscas utilizando os referidos descritores sem aspas.

No SciELO, operamos da mesma forma que no Portal CAPES, utilizando os descritores "história do ensino de biologia" e "história da disciplina de biologia", com e sem o uso de aspas. Sendo que não filtramos as buscas por ano/data e idioma em nenhuma das duas plataformas. Apenas delimitamos as buscas por assunto.

Após este processo de quantificação das publicações, dividimos os trabalhos pelos títulos em categorias criadas por nós. Devido ao grande número de produções recuperadas no portal de periódicos da CAPES, SciELO e na RFHB - num total de 1545 (mil quinhentos e quarenta e cinco) documentos - e como meio de organização dos dados, agrupamos os títulos dos trabalhos a partir de temas comuns. Nesta organização dos trabalhos recuperados, lemos todos os títulos previamente para ter uma ideia geral das produções; isto é, não criamos categorias a priori; mas, sim, agrupamos os trabalhos após uma leitura prévia dos títulos.

Decerto, tal organização pode reunir trabalhos que não necessariamente possuem o mesmo objeto de estudo. Neste sentido, ancoramos-nos nas orientações da Associação Brasileira de Normas Técnicas (ABNT), na qual coloca a construção dos títulos com o uso de palavras, expressões ou frases que sejam condizentes com o assunto ou o conteúdo do trabalho (ABNT, 2001). E quando tínhamos dúvida sobre o que o trabalho poderia versar, recorríamos aos resumos dos mesmos.

Em seguida, criamos categorias e agrupamos os trabalhos pelas titulações mais semelhantes. Isto é, os títulos que remetiam a um tema comum, eram contabilizados juntos a este. Alguns trabalhos puderam ser colocados em mais de uma categoria. Desta forma, vamos trabalhar neste artigo com o número de ocorrências. Além disso, certas categorias criadas estabelecem relações com campos reconhecidos de estudos, o que já anuncia os temas abordados nas pesquisas.

A seguir, apresentamos os resultados advindos da análise bibliométrica (realizada na RFHB, portal CAPES, e SciELO) com a aplicação do método quantitativo-descritivo. E, em resumo, desenvolvemos categorias por meio dos títulos dos trabalhos recuperados. Atentamos para os títulos e tivemos como mote as palavras "biologia", "ensino" e "disciplina" e para expressões/termos que pudessem remeter ao nosso objeto de estudo: História do Ensino de Biologia.

\section{ANÁLISE DA REVISTA "HISTÓRIA E FILOSOFIA DA BIOLOGIA": O QUE DIZEM OS DADOS?}

As publicações na RHFB iniciam no ano de 2006, com o volume 1 editado por Maria Elice Brzezinski Prestes, Lilian Al-Chueyr Pereira Martins e Waldir Stefano. Os artigos fazem parte de uma seleção de trabalhos apresentados no IV Encontro de Filosofia e História da Biologia, realizado em 2006, na Universidade Presbiteriana Mackenzie. Na apresentação do primeiro volume, os editores chamam a atenção para o crescimento do número de pesquisadores no Brasil interessados nos temas de Filosofia 
e História da Biologia, e as suas relações com o ensino de Biologia nos diferentes níveis de escolaridade (PRESTES, MARTINS e STEFANO, 2006).

Durante a realização deste encontro, foi fundada a Associação Brasileira de Filosofia e História da Biologia ( $\mathrm{ABFHiB})$, com $\mathrm{o}$ intuito de estimular professores e pós-graduandos a estudarem e pesquisarem na área; e estabelecer uma interface de comunicação e cooperação entre os interessados nos estudos de filosofia e a história da biologia (PRESTES, MARTINS e STEFANO, 2006). Neste sentido, nossa análise vai desde o volume 1 da revista, publicado em 2006, até o volume 14, com publicação no primeiro semestre de 2019 - o que corresponde a todas edições publicizadas no site até 20 de abril de 2020. Ao longo destes 13 anos, foram 241 (duzentos e quarenta e um) trabalhos divulgados pela revista e analisados por nós.

Inicialmente, em 2006, a RHFB publicava de forma anual; e, a partir de 2010, semestralmente. A média de trabalhos publicados ao longo dos 13 anos analisados é em torno de 18 por ano; não havendo interrupções das edições neste período. Isso nos indica a periodicidade da revista e um número consideravelmente alto de produções, tendo em vista a emergência do campo de estudos e pesquisas sobre a Filosofia e História da Biologia.

Com relação às categorias, criamos quatro a partir dos títulos dos trabalhos recuperados. Todas elas, como explicado nos caminhos metodológicos desta pesquisa, foram elaboradas após uma leitura prévia das titulações, que resultou no seguinte:

Quadro 1: detalhamento das categorias elaboradas a partir dos trabalhos publicados na RHFB.

\begin{tabular}{|l|l|}
\hline $\begin{array}{l}\text { 1) Figuras } \\
\text { representativas na } \\
\text { ciência/biologia/filosofia }\end{array}$ & $\begin{array}{l}\text { Nesta categoria, agrupamos os títulos dos trabalhos que trouxessem figuras } \\
\text { reconhecidas do campo da biologia e da ciência, como os naturalistas Charles } \\
\text { Darwin e Alfred Russel Wallace (ambos envolvidos com a teoria de evolução das } \\
\text { espécies); Lazzaro Spallanzani (estudioso italiano das Ciências Naturais); bem } \\
\text { como Aristóteles, Peter Lund, Buffon, René-Antoine Ferchault de Réaumur, } \\
\text { Francisco de Melo Franco, Francis Bacon, Gregor Johann Mendel, Louis Pasteur, } \\
\text { Robert Hook, entre outros. }\end{array}$ \\
\hline $\begin{array}{l}\text { 2) Teorias, leis, } \\
\text { conceitos, modelos e } \\
\text { concepções }\end{array}$ & $\begin{array}{l}\text { Agrupamos trabalhos que expusessem explicitamente estes vocábulos; e também } \\
\text { que anunciassem pesquisas sobre evolucionismo e darwinismo. Como exemplo, } \\
\text { podemos citar o artigo de Nélio Bizzo, intitulado "A teoria genética de Charles } \\
\text { Darwin e sua oposição ao mendelismo" (BIZzO, 2008). Repare que o título } \\
\text { apresenta a palavra "teoria" - o que faz com que ele se enquadre nesta categoria } \\
\text {-e o naturalista Charles Darwin, que faz o mesmo artigo ser considerado tanto } \\
\text { aqui quanto na categoria 1, a qual agrupa figuras representativas na } \\
\text { ciência/biologia/filosofia. É importante lembrar que este movimento de inserção } \\
\text { de um mesmo artigo em diferentes categorias ocorreu em muitos trabalhos. }\end{array}$ \\
\hline 3) Educação, ensino e \\
escola & $\begin{array}{l}\text { Os trabalhos que apresentassem estas palavras nos títulos foram agrupados nesta } \\
\text { categoria; estejam eles mencionando "ensino de biologia/ciência" ou apenas } \\
\text { ensino. Bem como as pesquisas que fossem voltadas para a educação, de uma } \\
\text { forma mais ampla, ou escola. }\end{array}$ \\
\hline 4) Temas diversos & $\begin{array}{l}\text { Por "temas diversos" pode-se entender todos os artigos/trabalhos que não se } \\
\text { enquadrem no que discorremos nas três primeiras categorias, por exemplo: } \\
\text { Museu nacional; condições de existência; grupo sanguíneo; autismo; psicopatia; } \\
\text { melancolia; eugenia, entre muitos outros assuntos. }\end{array}$ \\
\hline
\end{tabular}

Fonte: Autores, 2020 
Tivemos, então, as categorias: 1) Figuras representativas na ciência/biologia/filosofia; 2) Teorias, leis, conceitos, modelos e concepções; 3) Educação, ensino e escola; 4) Temas diversos. O gráfico abaixo expressa a ocorrência destes trabalhos de acordo com as categorias criadas.

Gráfico 1: Número total de documentos recuperados: 1545; sendo que um mesmo documento pode ser classificado em mais de uma categoria. Trabalhos com base na RHFB.

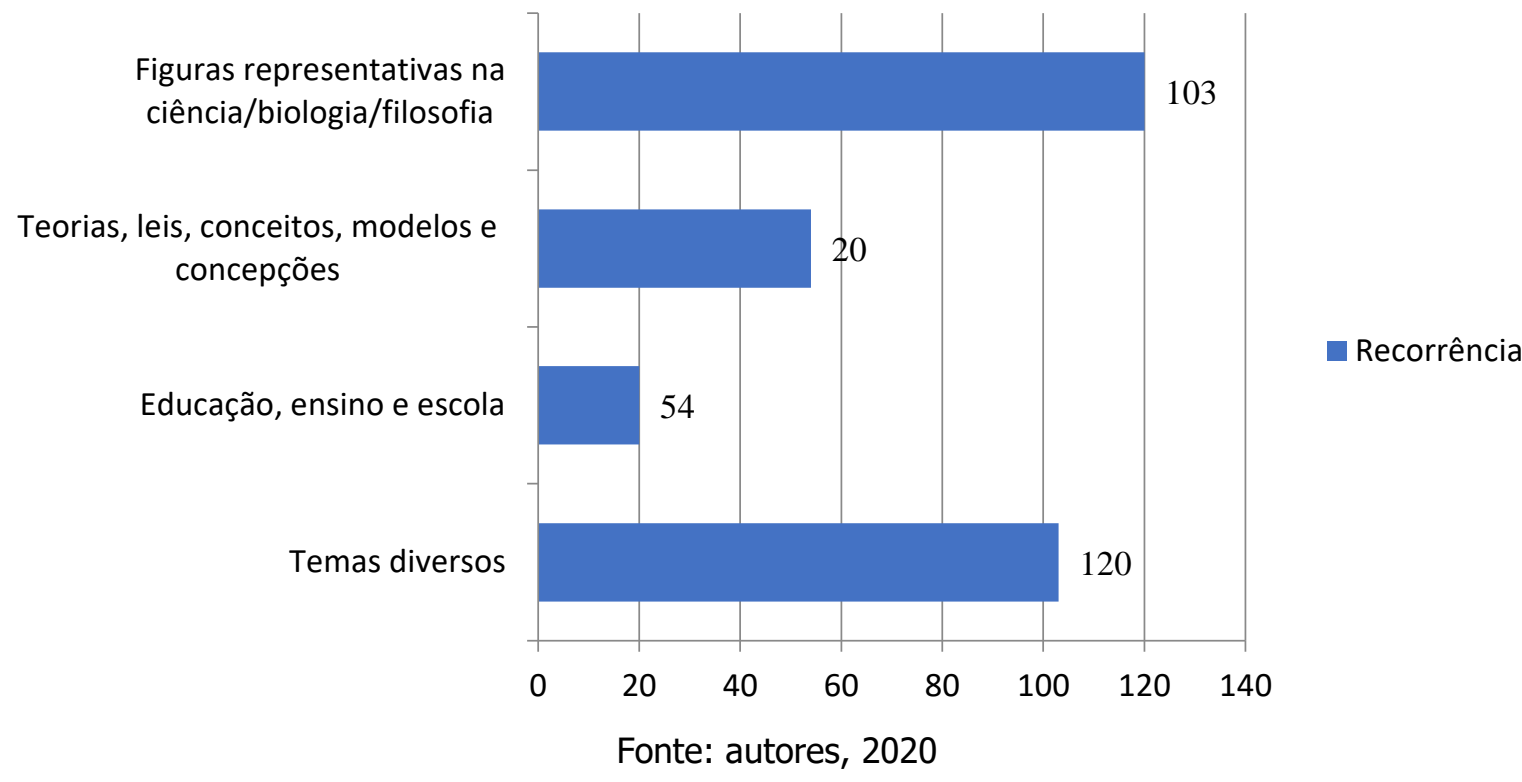

Como é possível perceber a partir do gráfico, a maioria dos trabalhos traz em seus títulos figuras representativas de áreas específicas da Biologia. Neste sentido, podemos pensar que muito da história da ciência, o que inclui a biologia, traz à tona cientistas, naturalistas ou outras figuras representativas para a área. Discorre-se sobre suas ideias, a forma como conduziram seus experimentos ou então suas leis, conceitos, modelos, concepções e teorias. Aqui, podemos traçar um paralelo entre as categorias (figuras representativas na ciência/biologia/filosofia) e a (teorias, leis, conceitos, modelos e concepções), pois recorrentemente os artigos recuperados na pesquisa citavam um naturalista e a teoria que o mesmo desenvolveu.

A título de exemplificação, tomamos o trabalho de Martins e Brito (2006), intitulado "As concepções iniciais de Thomas Hunt Morgan acerca de evolução e hereditariedade", e publicado no primeiro volume da RHFB; e o trabalho de Nunes, Cavassan e Brando (2013), "Frederic Edward Clements e o conceito de sucessão ecológica", com publicação no volume 8. Quando se trata destas figuras têmse títulos que colocam termos como: as concepções de; a teoria de; análise de; o universo em. E assim por diante. As preposições "de" e "em" podem nos indicar, em certa medida, a especificidade e o direcionamento dos trabalhos, tendo em vista que se referem especificamente a um determinado naturalista, filósofo, cientista.

Embora não objetivamos examinar na íntegra todos os trabalhos, ambos os títulos supracitados trazem os nomes de figuras da área, como o zoólogo e geneticista Thomas Hunt Morgan e o botânico Frederic Edward Clements. Num trabalho temos a "concepção" e, no outro, o "conceito". À vista disto, pode-se pensar na história da ciência e da biologia atrelada aos experimentos, pesquisas e práticas coordenadas por um determinado sujeito. Ou seja, em dadas circunstâncias, os pesquisadores ganham destaque e tem seu nome não somente marcado na história da ciência, como também na própria nomenclatura de doenças, síndromes ou estruturas corporais de seres vivos. Se pudéssemos fazer um comparativo com a história da sociedade como um todo, poderíamos traçar uma discussão 
entre as histórias de países e revoluções, as quais são vistas com frequência pelo olhar dos "vencedores"; marginalizando todo um grupo de pessoas em prol de uma única figura. Com a história da ciência que, por vezes, é resumida apenas a um cientista e seu experimento de sucesso, como se não tivessem tido colaborações, ou sido realizados muitos experimentos, por diferentes sujeitos, em distintos laboratórios/locais.

Sobre a categoria educação, ensino e escola, tem-se um total de 20 (vinte) ocorrências. Nenhum dos trabalhos articula ensino e educação à História do Ensino de Biologia de uma forma mais ampla. Os trabalhos, quando tratam de história, envolvem temas/assuntos/conteúdos específicos da área, tais como as produções: "Aspectos históricos e filosóficos do conceito de vida: contribuições para o ensino de biologia", de Corrêa et al (2008); "As estruturas celulares: o estudo histórico do núcleo e sua contribuição para o ensino de Biologia", de Batisteti et al (2009); ou como a produção de Brandão e Ferreira (2009), a qual está intitulada "O ensino de Genética no nível médio: a importância da contextualização histórica dos experimentos de Mendel para o raciocínio sobre os mecanismos da hereditariedade".

Os títulos que apresentamos no parágrafo acima trazem conceitos, como o de vida; estudo histórico do núcleo; ou então o ensino de genética e os experimentos realizados por Mendel. Todos eles se situam, embora entrelaçados com ensino e história, a partir de uma Biologia consolidada. Isto é, o interesse das produções mencionadas não é a história da Biologia enquanto área da ciência ou então da disciplina escolar. Tampouco vislumbra tratar da Biologia antes mesmo dela se tornar uma disciplina escolar.

Contudo, cabe relembrar, que nosso interesse na história da Biologia está a alguns passos atrás. Não buscamos investigar os conteúdos vistos dentro da disciplina de Biologia já existente. Recuamos um pouco mais, estamos antes disso. Nosso olhar, tanto nesta pesquisa bibliométrica quanto nos outros estudos a serem realizados, intenciona recuar até um passado em que não se tinha a disciplina ou matéria escolar de Biologia. Por isso, estes trabalhos que utilizamos para representar a categoria não farão parte de uma investigação de cunho qualitativo para contar a história do Ensino de Biologia. Assim como os outros que ainda vamos apresentar.

Com esse panorama geral das publicações da RFHB, constatamos que os documentos recuperados são voltados para histórias específicas do Ensino de Biologia. Ou seja, voltada a temas como núcleo e vida, ou então experimentos realizados por dada figura. Isso nos leva a refletir sobre uma possível escassez de pesquisas que tenham como objetivo construir uma história da emergência do ensino de Biologia. Estamos, por conseguinte, promovendo uma crítica às publicações da revista? Certamente não. Queremos apenas chamar atenção para um campo pouco explorado e que pode ser desbravado na seara acadêmica, especificamente nos estudos de Filosofia e História da Biologia.

\section{PORTAL CAPES: HISTÓRIA DO ENSINO DE BIOLOGIA}

Nesta seção, vamos apresentar as buscas que realizamos no portal de periódicos da CAPES. Para tanto, vamos dividir tal apresentação em dois momentos. No primeiro momento, as buscas a partir do descritor "História do Ensino de Biologia"; no segundo, "História da Disciplina de Biologia". Dito isso, passamos aos dados.

Utilizando o descritor "História do Ensino de Biologia", recuperamos 786 (setecentos e oitenta e seis) trabalhos, sendo 608 (seiscentos e oito) artigos; 163 (cento e sessenta e três) livros; 04 (quatro) 
bases de dados; 4 (quatro) recursos textuais; 01 (uma) resenha; 01(uma) tese - de acordo com o refinamento (ou divisão) dos resultados realizado pelo próprio portal.

Com relação às categorias, temos sete criadas a partir dos títulos, tendo como fonte o Portal CAPES, para o descritor "História do Ensino de Biologia. É importante relembrar que, assim como fizemos na análise da RHFB e destacamos na metodologia, as categorias foram elaboradas após uma primeira leitura das titulações, a saber: 1) Estudos de corpos, gêneros, sexualidades e raças/etnias; 2) Formação/concepções de professor; 3) Materiais didáticos e propostas pedagógicas/metodologias de ensino; 4) Ensino de disciplinas/temáticas; 5) Currículo e interdisciplinaridade; 6) Filosofia e história da ciência/biologia; 7) Temas diversos. Apesar de os nomes das categorias darem indicativos de quais temas os trabalhos elas reúnem, cabe pontuarmos detalhadamente cada uma no Quadro 2.

Quadro 2: categorias com o descritor "História do Ensino de Biologia"

\begin{tabular}{|l|l|}
\hline $\begin{array}{l}\text { 1) Estudos de corpos, gêneros, } \\
\text { sexualidades e raças/etnias }\end{array}$ & $\begin{array}{l}\text { Nesta categoria, agrupamos todos os trabalhos que expressam nos títulos } \\
\text { diversidade sexual, gênero, raça, etnias e estudos feministas. }\end{array}$ \\
\hline $\begin{array}{l}\text { 2) Formação/concepções de } \\
\text { professor }\end{array}$ & $\begin{array}{l}\text { Os títulos que apresentam temas como formação inicial e continuada de } \\
\text { professores, seja do Ensino Básico ou Superior; concepções de discentes } \\
\text { e graduandos; assim como referência ao Programa Institucional de Bolsas } \\
\text { de Iniciação à Docência (PIBID) fazem parte desta categoria. }\end{array}$ \\
\hline $\begin{array}{l}\text { 3) Materiais didáticos e propostas } \\
\text { pedagógicas/metodologias de } \\
\text { ensino }\end{array}$ & $\begin{array}{l}\text { Reunimos os títulos que anunciam estudos/análises de livro didático; usos } \\
\text { de materiais de ensino como jogos, documentários, memes, vídeo aulas, } \\
\text { entre outros. }\end{array}$ \\
\hline 4) Ensino de disciplinas/temáticas & $\begin{array}{l}\text { Com certa frequência, encontramos trabalhos que pontuam o ensino de } \\
\text { determinada área ou assunto, como: ensino religioso; ensino de história, } \\
\text { ensino de matemática; genética, evolução, ecologia, micologia. }\end{array}$ \\
\hline $\begin{array}{l}\text { 5) Currículo e } \\
\text { interdisciplinaridade }\end{array}$ & $\begin{array}{l}\text { Agrupamos os títulos que expressaram o campo dos estudos sobre } \\
\text { currículo escolar e/ou interdisciplinares. }\end{array}$ \\
\hline $\begin{array}{l}\text { 6) Filosofia e história da ciência } \\
\text { e/ou biologia }\end{array}$ & $\begin{array}{l}\text { Nesta foram agrupadas as temáticas envolvendo alguma história ou } \\
\text { filosofia da biologia ou da ciência. }\end{array}$ \\
\hline & $\begin{array}{l}\text { Por temas diversos, entendemos assuntos/títulos que não se enquadram } \\
\text { nas categorias já descritas, tais como: educação para o desenvolvimento } \\
\text { sustentável em espaços não formais; periodização dos estudos } \\
\text { linguísticos no Brasil; vestibular e processos seletivos no Brasil; história } \\
\text { da música; entre outros. }\end{array}$ \\
\hline 7) Temas diversos
\end{tabular}

Fonte: Autores, 2020.

Logo de início, numa primeira análise, é possível perceber que a maioria das categorias criadas não se vincula com a História do Ensino de Biologia. Os títulos trazem expressões, novamente, a assuntos específicos do campo da Biologia, como ensino de micologia (estudo dos fungos) e ensino de genética, por exemplo. A ideia de ensino posta nos trabalhos está ligada ao verbo ensinar; no sentido de transmitir estes conteúdos/assuntos no campo educacional.

Não podemos, com isso, afirmar inexistência de produções por não utilizarmos outras bases de dados e também por nos afastarmos de informações/ideias totalizantes. Mas conseguimos pontuar a escassez levando em consideração a amplitude do Portal CAPES. Uma biblioteca digital de referência no país e que, segundo Cendon e Ribeiro (2008), é um dos "principais mecanismos de atualização da 
comunidade acadêmica brasileira em relação à produção científica nacional e internacional" (p. 157). A seguir, apresentamos no gráfico 2 as categorias com o número de títulos recorrentes de cada uma.

Gráfico 2: Número total de documentos recuperados: 1545; sendo que um mesmo documento pode ser classificado em mais de uma categoria. Categorias criadas a partir do Portal de Periódicos da CAPES. Descritor utilizado: História do Ensino de Biologia

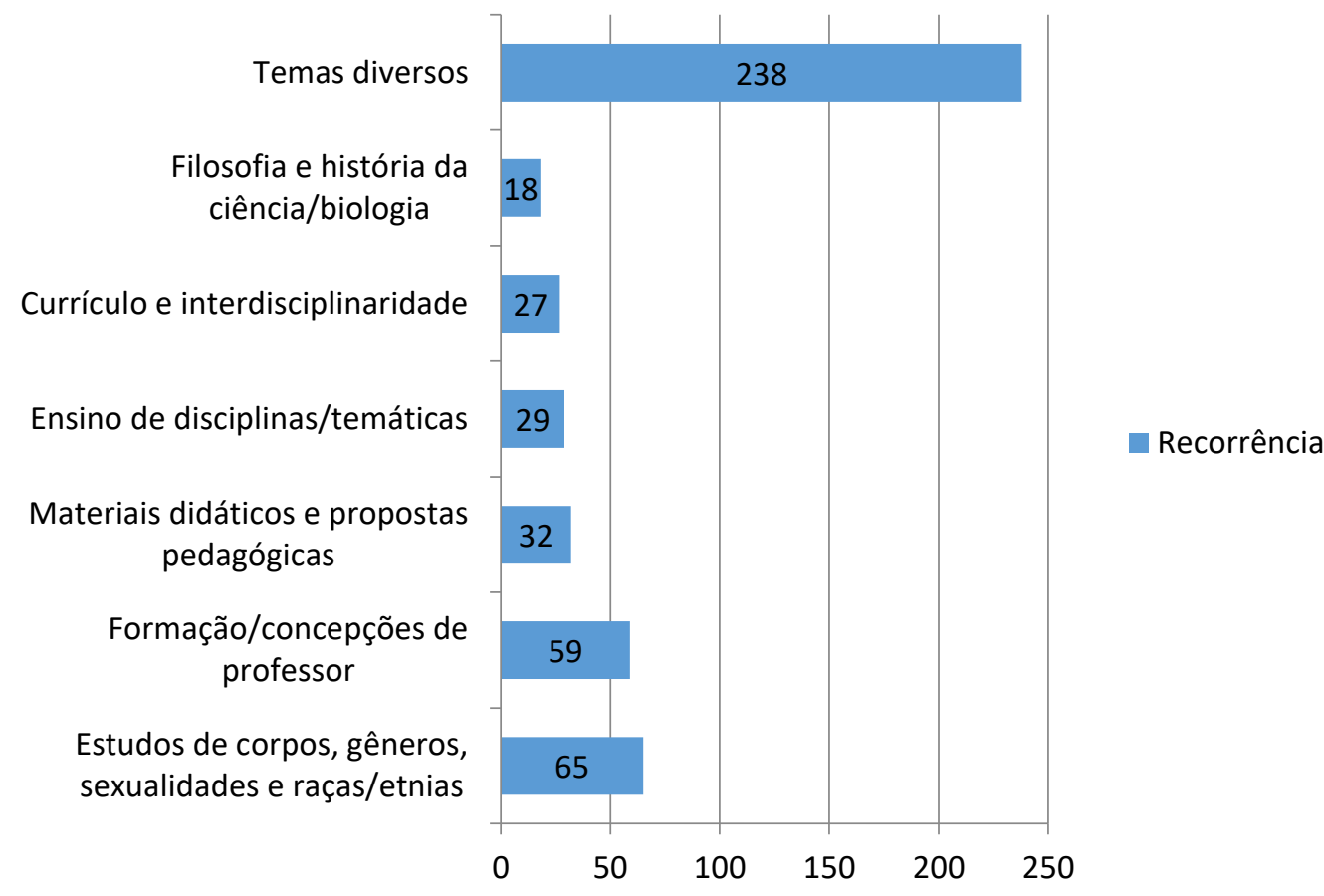

Fonte: Autores, 2020

Os estudos sobre corpos, gêneros, sexualidades, raças e etnias representam, exceto "temas diversos", a categoria com maior ocorrência. Surpreende-nos o alto número de temáticas que, a princípio, se afastam do escopo da nossa pesquisa. Entendemos que pesquisas que envolvem gênero e sexualidade, por exemplo, podem se vincular a hormônios - como o próprio trabalho Silva e Coutinho (2016), intitulado "Realidades colaterais e a produção da ignorância em livros didáticos de biologia: um estudo sobre os hormônios e a questão de gênero". Ou a produção recuperada de Molina e Santos (2018), que anuncia uma pesquisa sobre "Educação Sexual e currículo de ciências/biologia".

Esses resultados são reflexos do uso de um descritor mais amplo: História do Ensino de Biologia sem o uso de aspas; pois, quando o restringimos com o uso das aspas, não obtivemos resultados. Ou então quando buscamos no Portal CAPES por palavras-chave como biologia and história ou biologia and ensino os resultados foram extremamente altos - mais de 6 (seis) mil trabalhos - o que tornaria ainda mais amplo os descritores e se afastaria em demasia do tema de pesquisa.

A categoria 2, que se vincula à formação de professores, apresenta títulos de trabalhos imbricados na formação inicial e continuada de docentes. Muitos destes não mencionam ensino de ciências, biologia ou ciências da natureza, voltam-se a formação de professores de outras áreas da educação como, por exemplo, português e matemática. O mesmo acontece com a categoria 3, na qual reunimos os títulos que anunciam estudos/análises de livros didáticos, usos de materiais de ensino como jogos, documentários, entre outros. Em boa medida, podemos dizer que as três categorias mencionadas pouco expressam trabalhos voltados para o ensino de ciências e/ou biologia; e não se inscrevem no campo da História do Ensino de Biologia. 
Filosofia e história da ciência e/ou biologia, que corresponde a categoria 6, é a que possui o menor número de ocorrências, ainda que os descritores utilizados nos conduzisse para o oposto a isso. Se interrogarmos estes dados, nos deparamos com um campo recente. A filosofia e história da biologia é um continente emergente na pesquisa. A Associação Brasileira de Filosofia e História da Biologia (ABFHiB), como já pontuado anteriormente, foi fundada em 2006. De lá pra cá, como podemos ver na análise que fizemos tanto da revista quanto do portal CAPES, tem-se um contingente significativo de trabalhos, mas, ainda assim, é preciso preencher lacunas do conhecimento histórico.

No segundo momento da pesquisa no Portal CAPES, utilizamos o descritor: "História da Disciplina de Biologia". Decidimos ampliar o descritor inicialmente utilizado - ensino - para disciplina de Biologia, com o intuito de, justamente, encontrarmos possíveis produções nesta área. Levando em consideração que História das Disciplinas faz parte de um campo de estudos maior, abarcado pela História da Educação (ANJOS, 2013). Assim, tivemos 497 (quatrocentos e noventa e sete) documentos recuperados, divididos em: 352 (trezentos e cinquenta e dois) artigos; 142 (cento e quarenta e dois) livros; 02 (dois) resenhas; 1 (um) recursos textuais. Não tivemos com a busca teses e dissertações recuperadas.

Os resultados foram muito semelhantes quando utilizamos o descritor "História do Ensino de Biologia". Os títulos dos trabalhos apresentam pesquisas voltada para formação inicial ou continuada de professores, materiais didáticos ou ainda estudos sobre corpos, gêneros e sexualidades, o que se afasta em demasia do nosso objeto de estudo. Já no que tange às categorias, após a leitura prévia dos títulos dos trabalhos, conseguimos manter, basicamente, as mesmas, como pode ser visto: 1) Área médica/saúde; 2) Formação/concepção de professor; 3) Materiais didáticos e propostas pedagógicas/metodologias de ensino; 4) Estudos de corpos, gêneros, sexualidades e raças/etnias; 5) Ensino de ciências e/ou matemática; 6) Filosofia e história da ciência e/ou biologia; 7) Temas diversos.

Gráfico 3: Número total de documentos recuperados: 1545; sendo que um mesmo documento pode ser classificado em mais de uma categoria. Categorias criadas a partir do Portal de Periódicos da CAPES. Descritor utilizado: História da Disciplina de Biologia

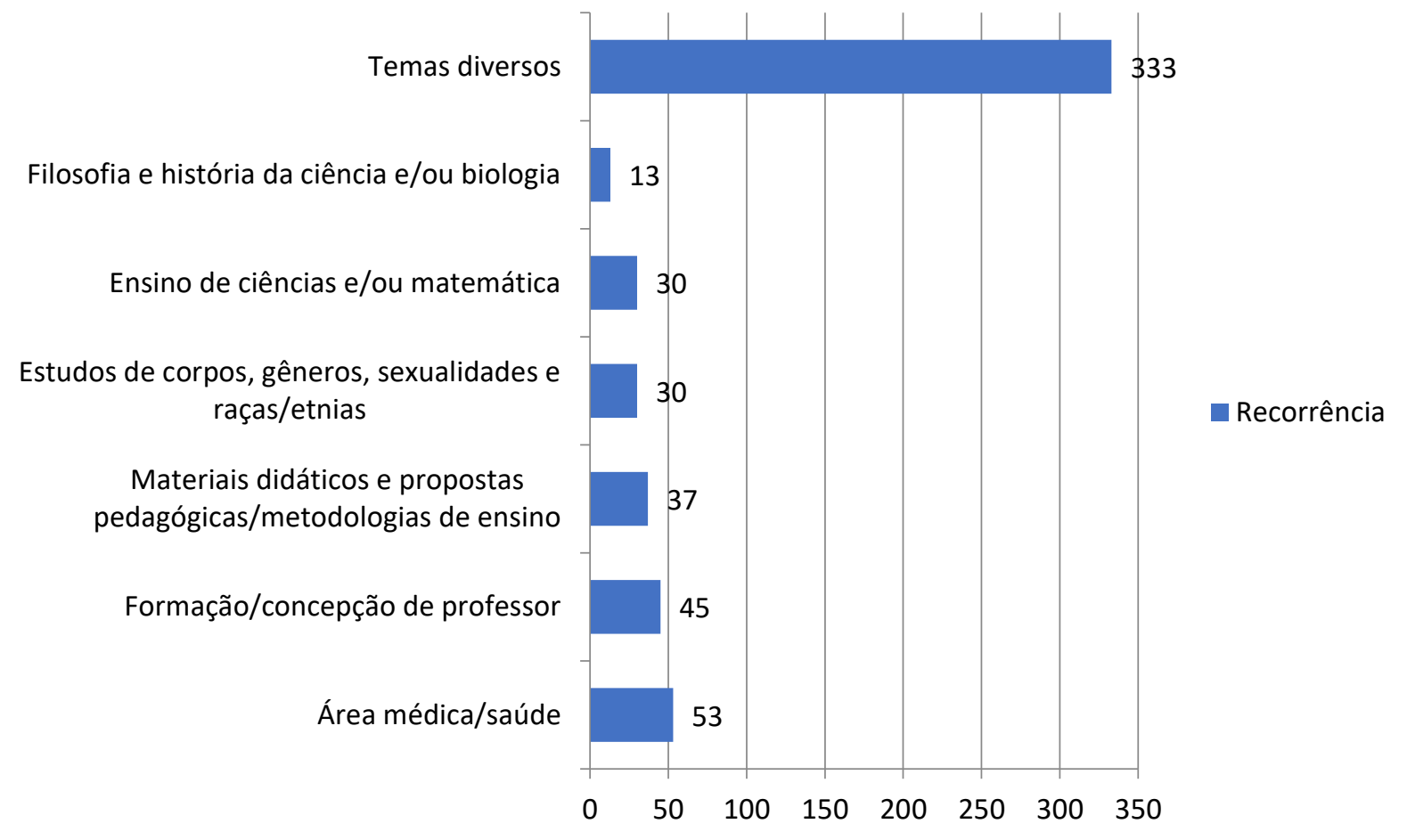

Fonte: Autores, 2020 
Comparando os descritores "História da Disciplina de Biologia" com "História do Ensino de Biologia", temos poucas alterações nas categorias criadas, assim como no número de trabalhos recuperados. Destacamos as categorias 1 e 5, "área médica e saúde" e "ensino de ciências e/ou matemática". Com exceção da categoria "temas diversos", trabalhos voltados para a área médica ou da saúde foram os mais recorrentes. Sobre eles, os títulos anunciavam estudos de doenças como a tuberculose, por exemplo, causas de mortes, e cuidados com o corpo. Por outro lado, chama-nos atenção para as produções voltadas para a matemática. Novamente podemos nos utilizar da ideia dos descritores amplos - o que, positivamente, nos permite resgatar o que está sendo produzido na área de interesse - mas nos coloca frente a trabalhos que fogem do objeto de estudo. Além disso, pode-se inquirir sobre a consolidação do campo da história da matemática.

Neste sentido, podemos observar que a história da biologia tem como principal evento representante o "Encontro de História e Filosofia da Biologia". Na matemática, segundo Valente (2017), tem-se visto, desde pelo menos o ano de 2011, a criação de eventos nacionais e internacionais voltados à discussão de estudos sobre história da educação matemática. O autor traz alguns exemplos, como: Encontro Nacional de História da Educação Matemática; e o Congresso Ibero-americano de História da Educação Matemática; International Conference on the History of Mathematics Education. Os eventos, de certa maneira, estabelecem uma rede comunicacional, de criação e de troca de conhecimentos, pesquisas, fontes e informações sobre o campo em questão - o que favorece, também, sua constituição enquanto área de pesquisa.

\section{HISTÓRIA DO ENSINO DE BIOLOGIA: ANÁLISE NA BIBLIOTECA ELETRÔNICA SCIELO}

Da mesma forma como conduzimos as buscas no Portal CAPES, procedemos na biblioteca eletrônica SciELO. A utilização dos descritores "história do ensino de biologia" e "história da disciplina de biologia", com o uso de aspas, não gerou resultados. Também não obtivemos resultados com o uso do descritor "história da disciplina de biologia", com e sem aspas.

Os 21 (vinte e um) trabalhos recuperados foram com o uso do descritor "história do ensino de biologia" (sem aspas). Os idiomas recuperados foram em português, inglês e espanhol, entre os anos de 2005 a 2018. Torna-se importante relembrar que em todas as plataformas analisadas não filtramos as buscas por ano/data e idioma; apenas por assunto.

O número de trabalhos recuperados na biblioteca SciELO, comparado com o Portal CAPES e a RHFB, é menor. Já as categorias criadas foram similares, a saber: 1) Ensino de biologia; 2) Filosofia e história da biologia; 3) Temas/conteúdos de biologia; 4) Temas diversos. As categorias "Filosofia e história da biologia" e "Temas diversos" seguem o mesmo entendimento explicado ao tratarmos das outras plataformas (CAPES e RFHB). A diferença está entre "Ensino de biologia" e "Temas/conteúdos de biologia", na qual a primeira reúne trabalhos que, especificamente, envolvem ensino, educação básica e/ou superior, escola e educação científica. E, a segunda, agrupa trabalhos que expressam a biologia em si e não trazem a ideia de educação e ensino. O gráfico abaixo mostra a ocorrência dos trabalhos nestas categorias: 
Gráfico 4: Número total de documentos recuperados: 1545; sendo que um mesmo documento pode ser classificado em mais de uma categoria. Categorias criadas a partir da biblioteca eletrônica SciELO. Descritor utilizado: História do Ensino de Biologia

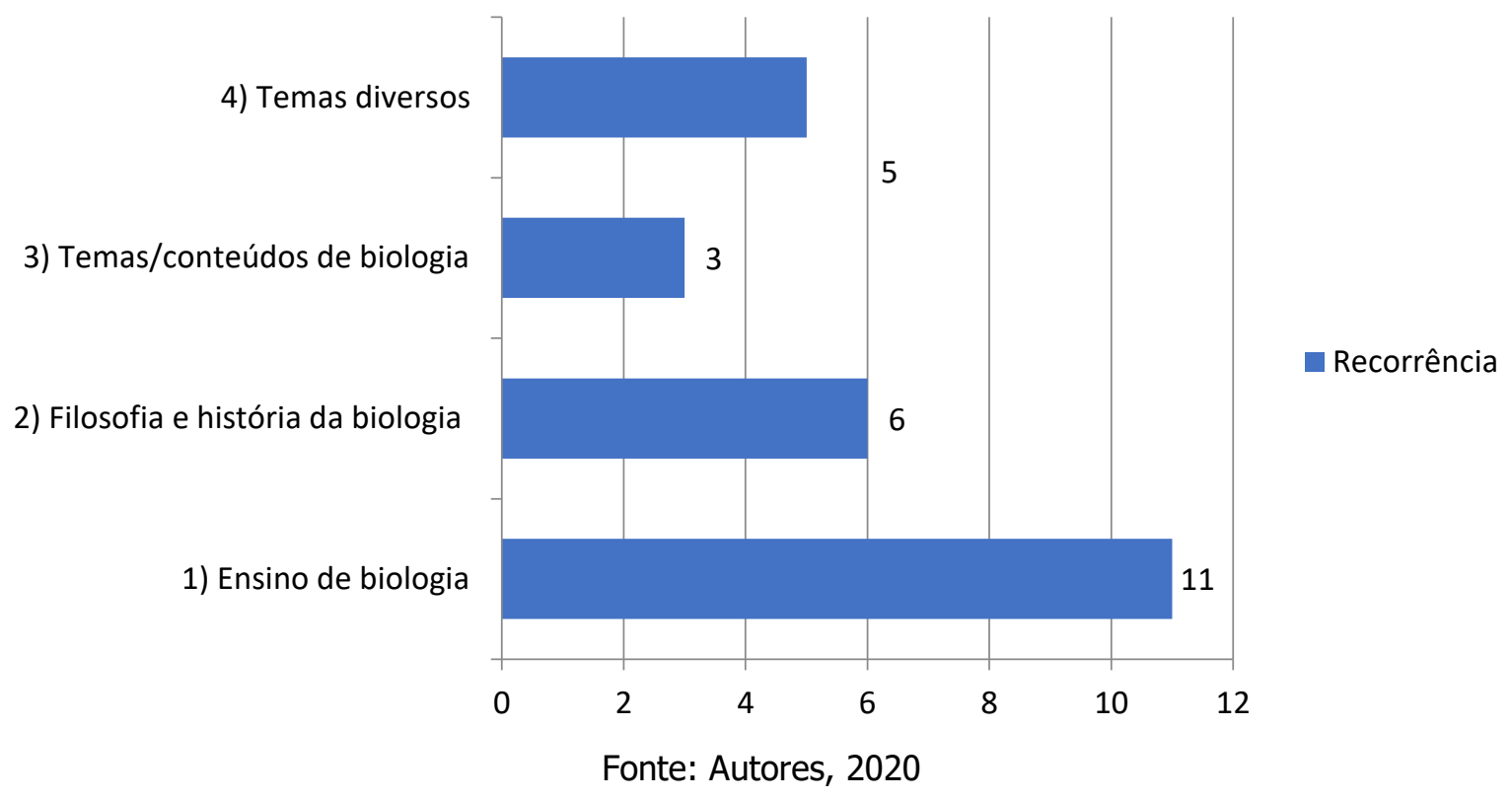

Por último, podemos dizer que nenhuma das categorias criadas agrupa trabalhos que tratem da emergência da História da Biologia - o que, certamente, não exime a riqueza das produções. Em se tratando da categoria 1, com maior ocorrência de trabalhos, os títulos perpassam por narrativas científicas no ensino de biologia (ARAUJO, AVANZI, e GASTAL, 2017); ensino religioso e implicações para o ensino de ciências e biologia (SELLES, DORVILLE e PONTUAL, 2016), bem como o movimento do sangue no corpo humano (DELIZOICOV, CARNEIRO e DELIZOICOV, 2004) entre outros assuntos concernentes ao ensino de biologia.

\section{CONSIDERAÇÕES FINAIS}

Procuramos com o presente artigo mostrar o número de produções envolvendo a História do Ensino de Biologia, disponíveis na RHFB, no Portal CAPES e na biblioteca eletrônica SciELO. O material recuperado não nos permitiu realizar uma análise qualitativa - devido a pouca relação com nosso objeto de estudo. Mas nos permitiu perceber com a análise quantitativa que há um número reduzido de estudos sobre história do ensino de biologia, comparado com a história da educação matemática, por exemplo. Além disso, destacamos a importância dos estudos bibliométricos para a história do ensino de Biologia. Mapear, quantificar e interpretar os resultados envolvendo estas pesquisas nas bases de dados contribui com o futuro da ciência, com o direcionamento a ser dado às pesquisas.

Essa questão do resultado "zero" pode ser também filosoficamente pensada a partir das críticas à ciência indutivista. Nas pesquisas científicas conduzidas indutivamente, a partir dos dados obtidos e das teorias que antecedem a organização dos mesmos, supostamente, chegaríamos a uma conclusão final sobre o tema da pesquisa; legitimando-a como válida. Não recuperamos produções específicas com esta temática, mas, mesmo assim, este ainda continua sendo um dado importante para a pesquisa. Quando apontamos uma possível inexistência de dada discussão ou mesmo de um objeto/tema de pesquisa na seara acadêmica, isso nos leva, talvez, a inaugurar uma série de novas discussões na pesquisa na área da história do ensino de biologia e, quiçá, na história e filosofia da 
biologia. Em suma, do ponto de vista acadêmico, sabemos que existe um trajeto a ser percorrido quando se trata de História do Ensino de Biologia.

Em se tratando do Portal CAPES, as categorias criadas para representar as produções, permitiramnos perceber que grande parte dos trabalhos recuperados se concentram nos estudos sobre corpos, gêneros, sexualidades, raças e etnias; área médica/saúde; formação de professores; e materiais didáticos e propostas pedagógicas. Sendo a categoria "temas diversos" a mais recorrente. Já o número de trabalhos recuperados na biblioteca eletrônica SciELO, considerada as proporções, comparado com o Portal CAPES, foi menor. Entretanto, os trabalhos recuperados se aproximam mais do tema Ensino de Biologia.

A análise na RHFB também nos mostrou que ainda é preciso avançar nos estudos sobre História do Ensino de Biologia, pensado de uma forma mais ampla, tendo em vista que os trabalhos de modo geral, quando tratam de história, envolvem temas/assuntos/conteúdos específicos da área, isto é: figuras representativas na ciência/biologia/filosofia; e histórias envolvendo teorias, leis, conceitos, modelos e concepções de cientistas/filósofos.

Neste artigo, ficou evidente para nós que a História do Ensino de Biologia faz parte de um campo de pesquisa e estudos pouco explorado. As buscas nos mostraram que a quantidade de pesquisas que tratam do Ensino de Biologia é baixa; assim como as obras que, mais especificamente, objetivam discorrer sobre a história da área. Com isso, acreditamos que as indagações empreendidas na introdução deste artigo, a lembrar: "quais temas do ensino de Biologia foram mais recorrentes nas buscas? Quais tipos de histórias do ensino de biologia estão sendo contadas e publicizadas nas plataformas analisadas? Quais (ou qual) assuntos podem necessitar maior atenção e/ou ênfases pela comunidade de pesquisadores interessados na História do Ensino de Biologia?" foram respondidas.

Por fim, acreditamos na necessidade de empreender pesquisas que tratam não somente do ensino de biologia, mas uma perspectiva histórica que leve em consideração a sua emergência. Estudos como estes contribuem para compreendermos tanto os movimentos que o constituíram - que são caros a pesquisas em educação - quanto para utilizarmos o passado para (re)pensar no presente esse ensino. Isto é, repensarmos a maneira como organizamos os conhecimentos/conteúdos no ensino de Biologia; discutirmos a imposição de regulamentos de caráter normativo para a educação; bem como indagar e construir estratégias para a condução do ensino de Biologia. Baseados nesses entendimentos, podemos ainda tomar atitudes e decisões com maior conhecimento e criticidade, enquanto professores e pesquisadores da área.

\section{REFERÊNCIAS DE OBRAS RECUPERADAS}

ARAUJO, Antônio; AVANZI, Maria Rita; GASTAL, Maria Luíza. Uma experiência de encontro entre narrativas autobiográficas e narrativas científicas no ensino de biologia para jovens e adultos. Ensaio Pesquisa em Educação em Ciências. v. 19, p. 1-19, 2017.

BATISTETI, Caroline Belotto; ARAÚJO, Elaine Sandra Nabuco; CALUZI, João José. As estruturas celulares: o estudo histórico do núcleo e sua contribuição para o ensino de biologia. Filosofia e História da Biologia, v. 4, p. 17-42, 2009.

BRANDÃO, Gilberto Oliveira; FERREIRA, Louise Brandes Moura. O ensino de Genética no nível médio: a importância da contextualização histórica dos experimentos de Mendel para o raciocínio sobre os mecanismos da hereditariedade. Filosofia e História da Biologia, v. 4, p. 43-63, 2009. 
BIZZO, Nelio. A teoria genética de Charles Darwin e sua oposição ao mendelismo. Filosofia e História da Biologia, v. 3, p. 317-333, 2008.

CORRÊA, André Luis; SILVA, Paloma Rodrigues; MEGLHIORATTI, Fernanda Aparecida; CALDEIRA, Ana Maria de Andrade. Aspectos históricos e filosóficos do conceito de vida: contribuições para 0 ensino de biologia. Filosofia e História da Biologia, v. 3, p. 21-40, 2008.

DELIZOICOV, Nadir Castilho; CARNEIRO, Maria Helena da Silva; DELIZOICOV, Demétrio. O movimento do sangue no corpo humano: do contexto da produção do conhecimento para o do seu ensino. Ciência \& Educação, v.10, n.3, p. 443-460, 2004.

MARTINS, Lilian Al-Chueyr Pereira; BRITO, Ana Paula de Oliveira Pereira de Morais. As concepções iniciais de Thomas Hunt Morgan acerca da evolução e hereditariedade. Filosofia e História da Biologia, v. 1, p. 175-189, 2006.

MOLINA, Ana Maria Ricci; SANTOS, Welson Barbosa. Educação sexual e currículo de ciências/biologia: desafios à prática docente. Revista Ibero-Americana de Estudos em Educação, v. 13, n. 03, p. 1149-1163, 2018.

NUNES, Patricia da Silva; CAVASSAN, Osmar; BRANDO Fernanda da Rocha. Frederic Edward Clements e o conceito de sucessão ecológica. Filosofia e História da Biologia, v. 8, n. 3, p. 617-626, 2013.

SELLES, Sandra Escovedo; DORVILLE, Luís Fernando Marques; PONTUAL, Leandro Vahia. Ensino religioso nas escolas estaduais do Rio de Janeiro: implicações para o ensino de ciências/biologia. Ciência \& Educação, v. 22, n.4, p.875-894, 2016.

SILVA, Fábio Augusto Rodrigues; COUTINHO, Francisco Ângelo. Realidades colaterais e a produção da ignorância em livros didáticos de biologia: um estudo sobre os hormônios e a questão de gênero. Investigações em Ensino de Ciências, v. 21, p. 176-194, 2016.

\section{REFERÊNCIAS GERAIS}

ANJOS, Juarez José Tuchinski. História das disciplinas escolares: quatro abordagens historiográficas. Revista Reflexão e Ação, v.21, n. esp., p.281-298, 2013.

AULER, Décio. Interações entre ciência-tecnologia-sociedade no contexto da formação de professores de ciências. 2002. 250f. Tese (Doutorado em educação) - Programa de pós-graduação em educação, Universidade Federal de Santa Catarina, Florianópolis, 2002.

ASSOCIAÇÃO BRASILEIRA DE NORMAS TÉCNICAS. Informação e documentação - trabalhos acadêmicos - apresentação: NBR 14724. Rio de Janeiro: ABNT, 2001.

CENDON, Beatriz Valadares; RIBEIRO, Nádia Ameno. Análise da literatura acadêmica sobre o portal periódico CAPES. Informação \& Sociedade: Estudos, v.18, n.2, p. 157-178, 2008.

DELIZOICOV, Demétrio; ANGOTTI, José André Angotti; PERNAMBUCO, Marta Maria. Ensino de ciências: fundamentos e métodos. São Paulo: Cortez, 2002.

GUEDES, Vânia; BORSCHIVER, Suzana. Bibliometria: uma ferramenta estatística para a gestão da informação e do conhecimento, em sistemas de informação, de comunicação e de avaliação científica e tecnológica. Encontro Nacional de Ciência da Informação, v. 6, p. 1-18, 2005. 
KONDER. O Ensino de Ciências no Brasil: um breve resgate histórico In: CHASSOT, Ático. e Oliveira, Renato José. (org). Ciência, ética e cultura na educação. São Leopoldo: Ed. UNISINOS, 1998, p. 25.

MARANDINO, Martha; SELLES, Sandra Escovedo; FERREIRA, Marcia Serra. Ensino de Biologia: histórias e práticas em doferentes espaços educativos. São Paulo: Cortez, 2009.

KRASILCHIK, Myriam. Reformas e realidade: o caso do ensino das ciências. Revista Perspectiva, v.14, n.1, p.85-93, 2000.

LINSINGEN, Irlan von. Perspectiva educacional CTS: aspectos de um campo em consolidação na América Latina. Ciência \& Ensino, v. 1, n. especial, p. 1-19, 2007.

PRESTES, Maria Elice Brzezinski; MARTINS, Lilian Al-Chueyr Pereira; STEFANO, Waldir. Apresentação. Filosofia e História da Biologia, v. 1, p. 1-4, 2006.

VALENTE, Wagner Rodrigues. A internacionalização da pesquisa em História da Educação Matemática: movimentos de criação de um novo campo disciplinar. Cadernos de História da Educação, v.16, n.3, p. 610-618, 2017.

PRITCHARD, 1969. P.157. In: SANTOS; KOBACHI. Bibliometria, Cientometria, Infometria: conceitos e aplicações. Revista Pesquisa brasileira em Cientometria e Infometria, Brasília, v.2, n.1, p.155-172, 2009. 